\title{
Laypeople's Perspective of Esthetically Pleasing Smile in Kingdom of Saudi Arabia: A Cross-sectional Survey
}

\author{
Fatima AlOtaibi ${ }^{1}$, Maha Altamami $^{2}$, Noura Alsuwailem ${ }^{3}$, Latifah M Almasaud ${ }^{4}$, Refah A AlSubaie ${ }^{5}$, Rayada A Alhabeb ${ }^{6}$
}

\begin{abstract}
Aims: This study aimed to identify the self-perceived acceptable and pleasant smile characteristics and preferred dental esthetic treatments among laypersons from Kingdom of Saudi Arabia.

Materials and methods: This was a cross-sectional survey conducted among laypeople in Riyadh city. A structured, close-ended, and selfadministered questionnaire was distributed through social media to assess the participant's satisfaction with their smiles and desire to improve their smiles through various esthetic treatment modalities.

Results: Majority of the participants were female $(87 \%, n=783)$ compared to the male $(13 \%, n=117)$. A total of 355 (39.4\%) subjects were dissatisfied with the color of their teeth and the level of dissatisfaction was higher among female, 317 (89.3\%) compared to the male, 38 (10.7\%). Moreover, younger participants showed significantly higher dissatisfaction with color of their teeth compared to the other age groups $(p=0.002)$. Gender $(p=0.001)$ and age $(p=0.000)$ of the study subjects were found to be significantly associated with different whitening procedures. Similarly, education of the study participant is significantly associated with satisfaction with the appearance of teeth during smiling $(p=0.028)$. Pointed canines (75.7\%), gummy smile (88.6\%), wide smile $(95.7 \%)$, and gap between the teeth $(99.4 \%)$ were found to be significantly less attractive among study participants.

Conclusion: The findings of this study revealed that perception of color and dental appearance of the teeth varies among different subjects. Hence, understanding the layperson's opinion about the color of the teeth and appearance is important parameters in designing esthetically attractive smile for the patients.

Clinical significance: Laypeople's perception of esthetically pleasing smile is influenced by age, gender, and education of the individuals. Hence, while designing esthetically pleasing smile, these factors should be considered to get best clinical outcomes.

Keywords: Diastema, Esthetic, Gummy smile, Laypeople, Smile, Treatment.

World Journal of Dentistry (2019): 10.5005/jp-journals-10015-1662
\end{abstract}

\section{INTRODUCTION}

Merriam Webster dictionary defines esthetics as a branch of philosophy that deals with attractiveness and beauty. In dentistry, esthetics is described as "the bright, beautiful, but believable" teeth appearance. ${ }^{1}$ A healthy beautiful smile has a great impact on personality and the psychosocial well-being of individuals. ${ }^{2-4}$

Smile esthetic has been studied by using a variety of perspectives and methods, and many proportions were introduced in dentistry such as golden proportions, red proportions, and width to height ratio, the apparent contact dimension, and lateral incisor position in a smile. The golden proportion and facial analysis have been considered the ideal and most desirable in evaluation of symmetrical, dominance, and harmonious in teeth arrangement and in the application of esthetic dental treatment. ${ }^{5}$

Understanding the positions and the relationship among teeth and the proper dimensions of tooth display, size, length, and width, in accordance of the different landmarks in the oral cavity and a comprehensive facial analysis are all considered in any restorative intervention requiring an esthetically pleasing appearance. ${ }^{6,7}$ Many individuals are seeking various esthetic treatment modalities such as direct and indirect composite restorations, micro-abrasion, crowns, esthetic veneers, and so forth. ${ }^{8}$

There is always some kind of discrepancy between the patient and dentist perception of dentofacial esthetics. Moreover, golden proportion and facial analysis measures, shade, and shape selections might interfere with the differences in esthetic standards and perceived patient's satisfaction. While designing esthetically
${ }^{1-5}$ Department of Restorative Dentistry, College of Dentistry, Riyadh Elm University, Riyadh, Kingdom of Saudi Arabia

${ }^{6}$ Department of Restorative Dentistry, Mustaqbal University, Burayda, Alqassim, Kingdom of Saudi Arabia

Corresponding Author: Fatima AlOtaibi, Department of Restorative Dentistry, College of Dentistry, Riyadh Elm University, Riyadh, Kingdom of Saudi Arabia, e-mail: alotaibi.f.86@gmail.com

How to cite this article: AlOtaibi F, Altamami M, Alsuwailem N, et al. Laypeople's Perspective of Esthetically Pleasing Smile in Kingdom of Saudi Arabia: A Cross-sectional Survey. World J Dent 2019;10(5): 364-373.

Source of support: Nil

Conflict of interest: None

acceptable smile that fulfil patient's demand and expectations, range of parameters should be taken into considerations instead of ideal parameters. Clinicians should give full considerations for the subjective measurements rather than focusing on values and ratios. $^{9-12}$

There is insufficient documentation about the subjective measures of acceptable and pleasant smile among laypersons in Kingdom of Saudi Arabia. Hence, this study aimed to identify the self-perceived acceptable and pleasant smile characteristics and preferred dental esthetic treatments among laypersons from Kingdom of Saudi Arabia.

() The Author(s). 2019 Open Access This article is distributed under the terms of the Creative Commons Attribution 4.0 International License (https://creativecommons. org/licenses/by-nc/4.0/), which permits unrestricted use, distribution, and non-commercial reproduction in any medium, provided you give appropriate credit to the original author(s) and the source, provide a link to the Creative Commons license, and indicate if changes were made. The Creative Commons Public Domain Dedication waiver (http://creativecommons.org/publicdomain/zero/1.0/) applies to the data made available in this article, unless otherwise stated. 


\section{Materials and Methods}

The study proposal was submitted to Research Center of Riyadh Elm University and approval for the research was obtained (registration number FRP/2018/199). The Institutional Review Board formally approved the study RC/IRB/2018.

This cross-sectional study was carried out from June to July 2018. Nine-hundred laypersons from the Riyadh city participated in this study (female $=783$ and male $=117$ ). Age of the study participants ranged between 17 years and 68 years.

A structured, close-ended, and self-administered questionnaire was distributed through social media to the laypersons in Riyadh city. Satisfaction with the smile and desire to improve it through various esthetic treatment of tooth whitening, veneers or lumineers, dental crowns, and tooth-colored fillings modalities was assessed by showing various Figures 1 and 2. The questionnaire utilized in this study consisted of 14 items (Given at the end of this article). The first part of the questionnaire consisted of information on age, gender, and educational level of the study participants. While second and third parts assessed the satisfaction with the color, alignment, position of teeth, and desired treatment to improve appearance.

Forward and backward translation method was employed to translate the English version of the questionnaire into Arabic language by bilingual English and Arabic experts. The questionnaire was prepared in both Arabic and English languages and pretested among a small group of subjects. Changes to the questionnaire were made as needed to ensure comprehension and rendition of responses. After obtaining adequate validity and reliability, the final form of the questionnaire was distributed through emails using survey monkey. Later on excel sheets containing the questionnaire responses were downloaded and scanned for any missing information. All the responses were coded and then transferred to the statistical analysis software for further analysis.

\section{Statistical Analysis}

All the data were analyzed by using the statistical package for social sciences (SPSS version 21, Armonk, NY: IBM Corp., USA). Descriptive statistics of frequency distribution and percentages were calculated. Further, the association between categorical variables was analyzed by using $\mathrm{Chi}$-square tests. For all statistical analysis purposes, the significance level was set at $p \leq 0.05$.

\section{Results}

A total of 900 subjects participated in this study. Most of the participants 783 (87\%) were female, aged between 22 years and 25 years 367 (40.8\%), having bachelors 609 (67.7\%) degree qualification. Almost, 355 (39.4\%) and study participants were not satisfied and 190 (21.2\%) were satisfied with the color shade of their teeth (Table 1).

The relationship of age, gender, and education with the satisfaction of teeth color shade was assessed by using Chi-square test. It was found that the study participants aged 17-21 years $77(40.5 \%)$ were the most satisfied with the color shade of the teeth followed by others age groups. Satisfaction of color shade was found to be significantly related to the age of the study participants $(p=0.000)$. However, education and gender did not show any significant relationship with the color shade of the teeth as shown in Table 2.

Study participants with bachelor's degree qualification demonstrated higher responses toward satisfaction with the appearance of teeth during the smiling followed by others. A statistically significant difference was observed between different categories of education ( $p=0.028$ ), while age and gender did not show any significant differences in satisfaction with the appearance of teeth during the smiling (Table 3).
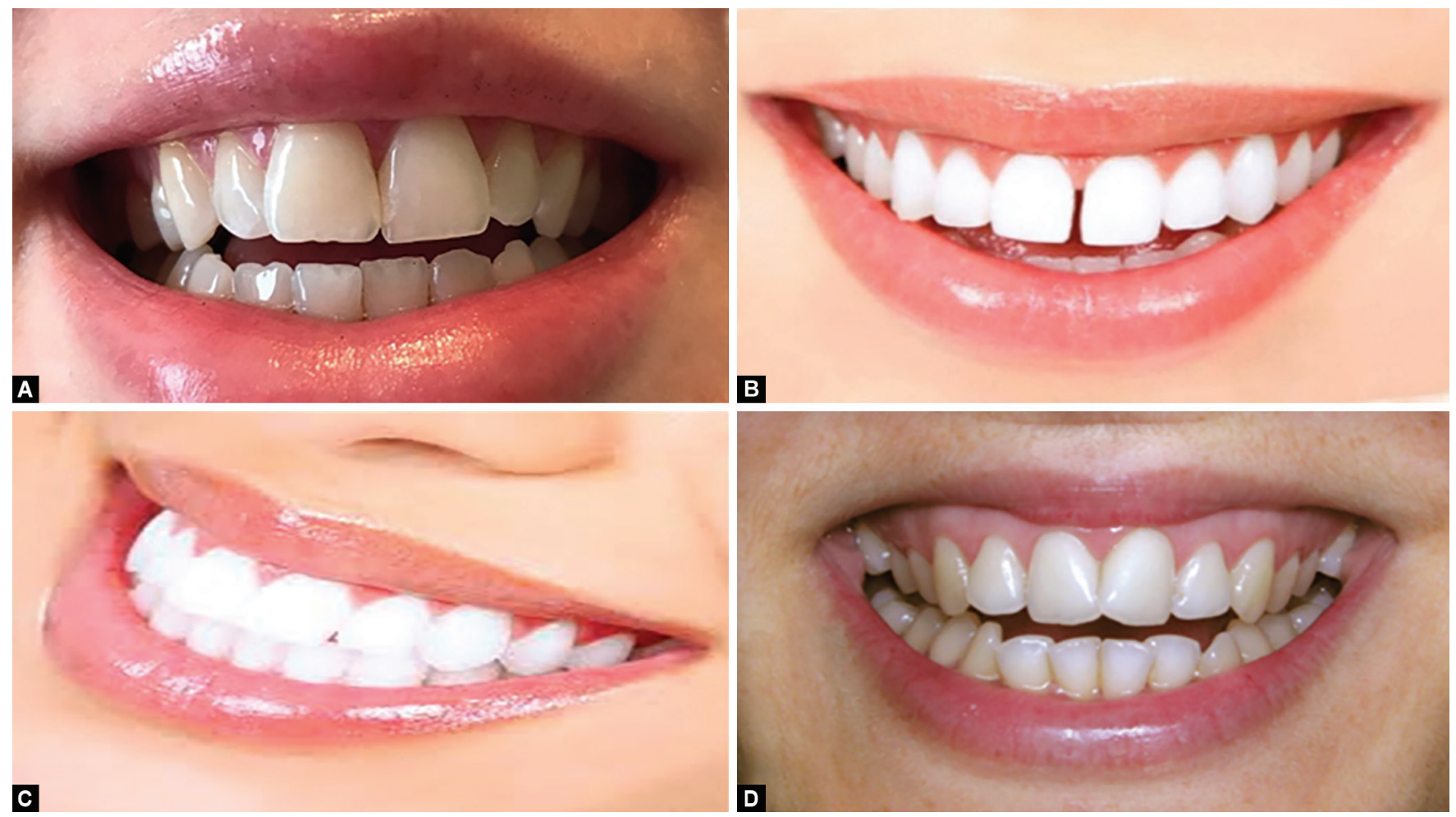

Figs $1 A$ to $D$ : Different smile figures 

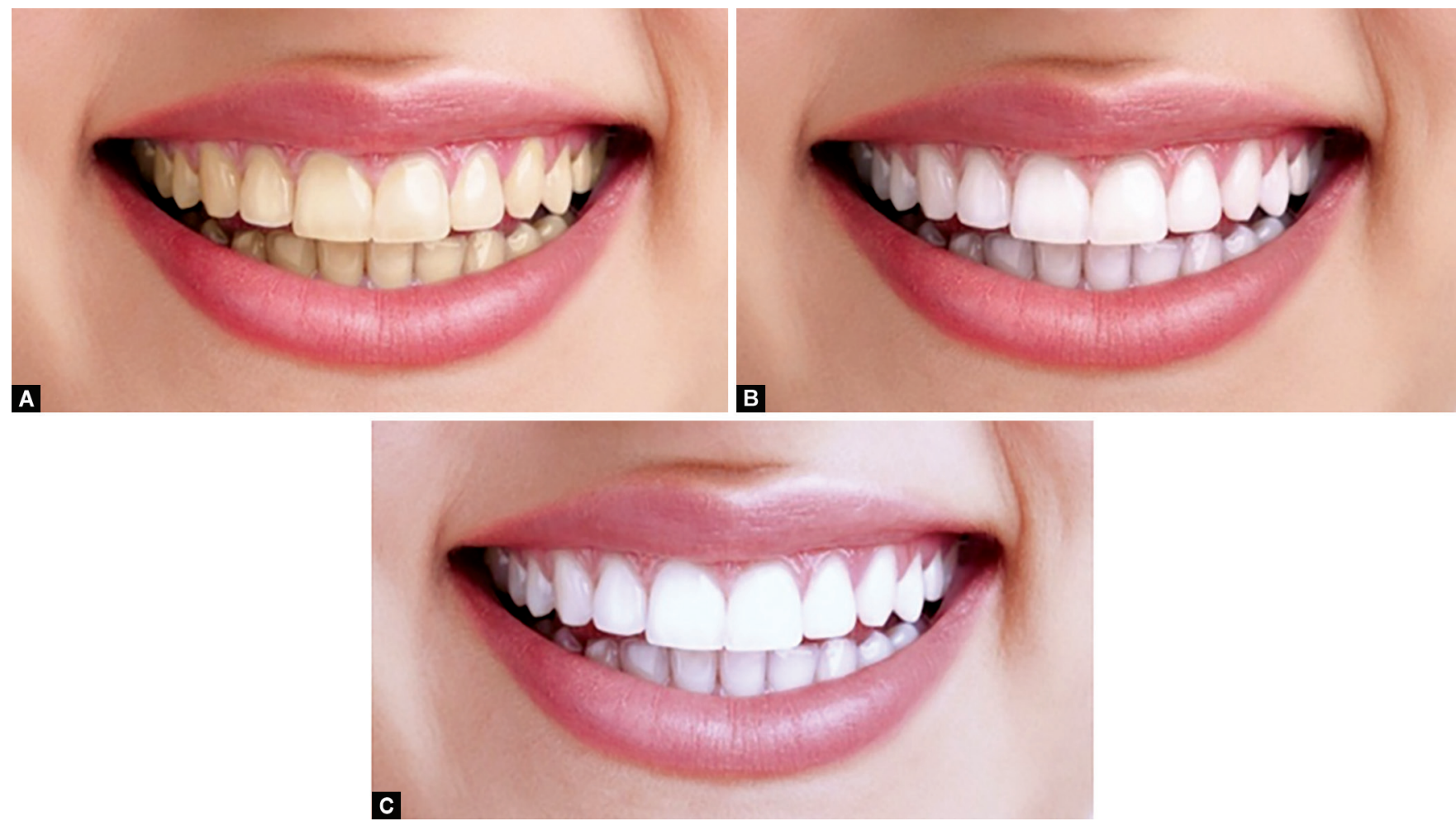

Figs 2A to C: Different colors of teeth

Table 1: Characteristics of the study participants $(n=900)$

\begin{tabular}{llrr}
\hline Characteristics & & $n$ & $\%$ \\
\hline Gender & Female & 783 & 87.0 \\
& Male & 117 & 13.0 \\
Age (years) & $17-21$ & 361 & 40.1 \\
& $22-25$ & 367 & 40.8 \\
& 25 and above & 172 & 19.1 \\
Education & High school & 165 & 18.3 \\
& Bachelor's degree & 609 & 67.7 \\
& Master's degree & 62 & 6.9 \\
& PhD & 12 & 1.3 \\
Satisfaction with & Yes & 52 & 0.8 \\
the color shade & No & 190 & 21.2 \\
of teeth & Yes, but I wish they were whiter & 355 & 39.4 \\
& & 355 & 39.4 \\
\hline
\end{tabular}

Smile attractiveness was enquired among study participants by showing four figures. Figure $1 \mathrm{~A}$ was considered more attractive by $285(31.7 \%)$ while $615(68.3 \%)$ study participants viewed it as less attractive. Various educational categories showed significant differences in attractiveness of Figure $1 \mathrm{~A}$. When asked about Figure 1B, 896 (99.6\%) study participants mentioned it as unattractive without any significant differences in gender, age, or educational levels. Three-fourth 675 (75.0\%) of the study participants felt that Figure 1C was less attractive while 225 (25.0\%) considered it as more attractive. Attractiveness of Figure $1 \mathrm{C}$ differed significantly across various age $(p=0.000)$ and educational ( $p=0.016$ ) categories. Similarly, high percentage of subjects 792 (88.0\%) felt Figure 1D less attractive compared to the 108 (12.0\%) who felt it more attractive. Age categories showed significant differences with regard to the attractiveness of the teeth (Table 4).

Most of the study participants considered small teeth 854 (94.9\%), pointed canines 681 (75.7\%), gummy smile 797 (88.6\%), wide smile 861 (95.7\%), and gap between the teeth 895 (99.4\%) were less attractive. Gender of the study participant was found to be significantly related to less attractiveness of the gummy smile $(p=0.000)$. While age showed significant differences with regard to the attractiveness of the pointed canines $(p=0.007)$ and wide smile $(p=0.007)$. However, educational level did not show any significant relationship with the perceived attractiveness of the smile (Table 5). More than half 532 (59.1\%) of the study participants perceived Figures $2 A$ and B 367 (40.8\%) tooth color were more attractive, while tooth color displayed in Figure $2 \mathrm{C}$ was least attractive (Table 6).

Female vs male esthetic preferences for teeth bleaching (34.6\% vs $35.9 \%)$, veneers $(21.85 \%$ vs $4.3 \%)$, and scaling and polishing ( $24.1 \%$ vs $32.5 \%)$ were recorded. However, higher percentage of male did not prefer esthetic treatment compared to the female. In general, esthetic treatment preferences differed significantly between genders. Similarly, age categories of the study participants demonstrated significant differences with regard to the esthetic treatment preferences. However, educational level of the participants did not show any statistically significant difference in the esthetic preferences (Fig. 3).

\section{Discussion}

Perceived smile and appearance differs between individuals as well as in populations. ${ }^{13,14}$ This study demonstrated that $39.4 \%$ of the participants were dissatisfied with the color shade of their teeth. This finding is lower than Turkish $55.1 \%^{15}$ and Chinese $52.6 \%{ }^{16}$ studies and higher than that reported in United States 34\%. ${ }^{17}$ 


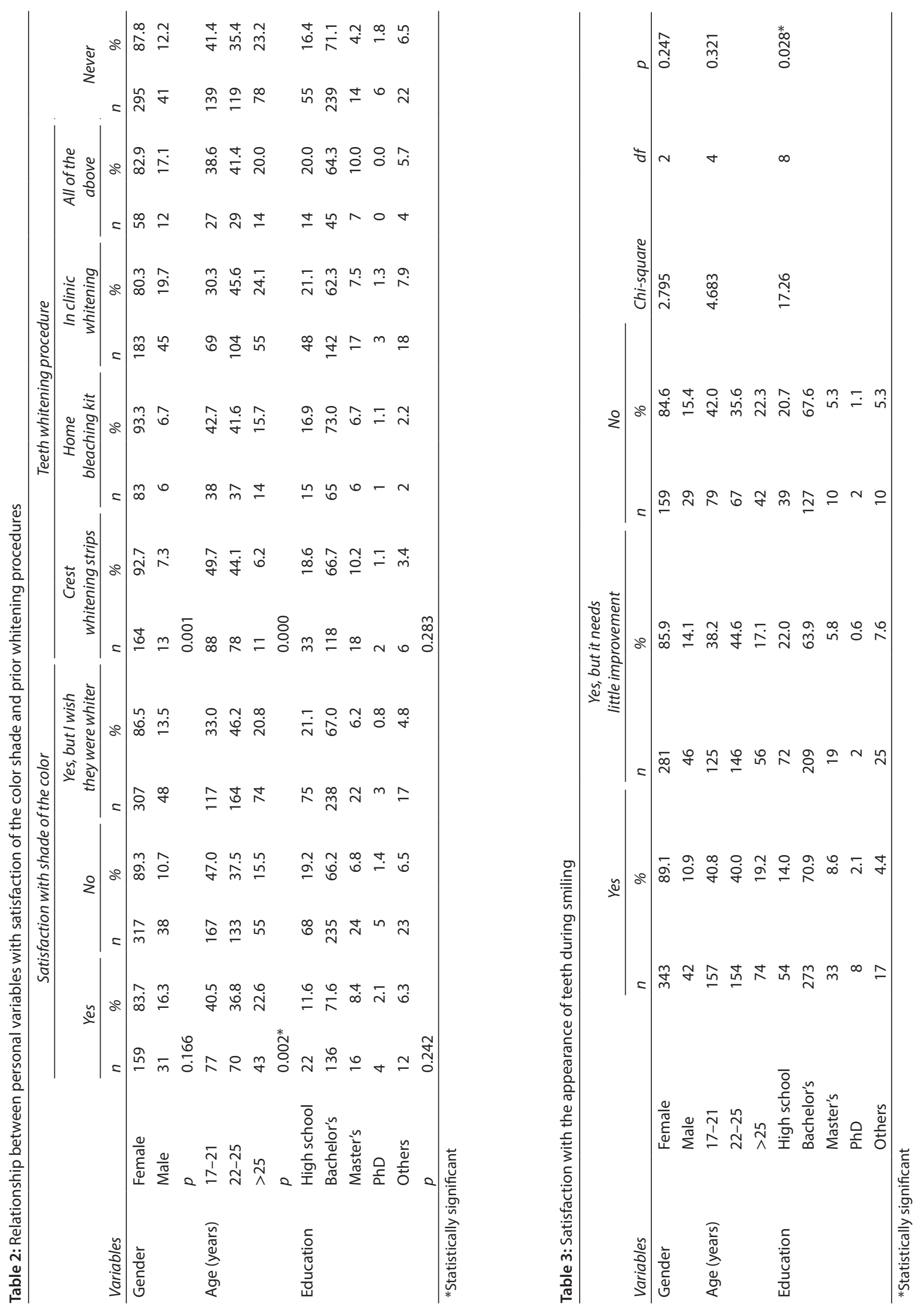


Table 4: Perceived smile attractiveness among the study participants

\begin{tabular}{llllll}
\hline Pictures & Less attractive $n(\%)$ & More attractive $n(\%)$ & Gender $p$ value & Age $p$ value & Education $p$ value \\
\hline Figure 1A & $615(68.3)$ & $285(31.7)$ & 0.388 & 0.182 & $0.031^{*}$ \\
Figure 1B & $896(99.6)$ & $4(0.4)$ & 0.474 & 0.154 & 0.528 \\
Figure 1C & $675(75.0)$ & $225(25.0)$ & 0.954 & $0.000^{*}$ & $0.016^{*}$ \\
Figure 1D & $792(88.0)$ & $108(12.0)$ & 0.534 & $0.023^{*}$ & 0.469 \\
\hline
\end{tabular}

*Indicates $p<0.05$

Table 5: Effect of teeth and gums on perceived smile

\begin{tabular}{|c|c|c|c|c|c|c|}
\hline Variables & & $n$ & $\%$ & Gender $p$ value & Age $p$ value & Education $p$ value \\
\hline \multirow[t]{2}{*}{ Small teeth } & Less attractive & 854 & 94.9 & 0.373 & 0.196 & 0.058 \\
\hline & More attractive & 46 & 5.1 & & & \\
\hline \multirow[t]{2}{*}{ Pointed canines } & Less attractive & 681 & 75.7 & 0.415 & $0.007^{*}$ & 0.458 \\
\hline & More attractive & 219 & 24.3 & & & \\
\hline \multirow[t]{2}{*}{ Gummy smiles } & Less attractive & 797 & 88.6 & $0.000^{*}$ & 0.173 & 0.337 \\
\hline & More attractive & 103 & 11.4 & & & \\
\hline \multirow[t]{2}{*}{ Wide smile } & Less attractive & 861 & 95.7 & 0.347 & $0.007^{*}$ & 0.649 \\
\hline & More attractive & 39 & 4.3 & & & \\
\hline \multirow[t]{2}{*}{ Gap between the teeth } & Less attractive & 895 & 99.4 & 0.641 & 0.066 & 0.729 \\
\hline & More attractive & 5 & 0.6 & & & \\
\hline
\end{tabular}

*Statistically significant

Table 6: Perceived attractiveness of tooth color among the study participants

\begin{tabular}{|c|c|c|c|c|c|c|c|c|c|c|c|c|}
\hline \multirow[b]{2}{*}{ Tooth color } & \multirow[b]{2}{*}{$n$} & \multirow[b]{2}{*}{$\%$} & \multicolumn{2}{|c|}{ Gender (\%) } & \multicolumn{3}{|c|}{ Age in years (\%) } & \multicolumn{5}{|c|}{ Education (\%) } \\
\hline & & & $F$ & $M$ & $17-21$ & $22-25$ & $>25$ & $H S$ & $B D$ & $M D$ & $P h D$ & Other \\
\hline Figure $2 \mathrm{~A}$ & 532 & 59.1 & 61.0 & 46.2 & 54.3 & 58.0 & 71.5 & 52.7 & 60.9 & 69.4 & 75.0 & 42.3 \\
\hline Figure 2B & 367 & 40.8 & 38.8 & 53.8 & 45.7 & 42.0 & 27.9 & 46.7 & 39.1 & 30.6 & 25.0 & 57.7 \\
\hline Figure $2 \mathrm{C}$ & 1 & 0.1 & 0.1 & 0.0 & 0.0 & 0.0 & 0.6 & 0.6 & 0.0 & 0.0 & 0.0 & 0.0 \\
\hline
\end{tabular}

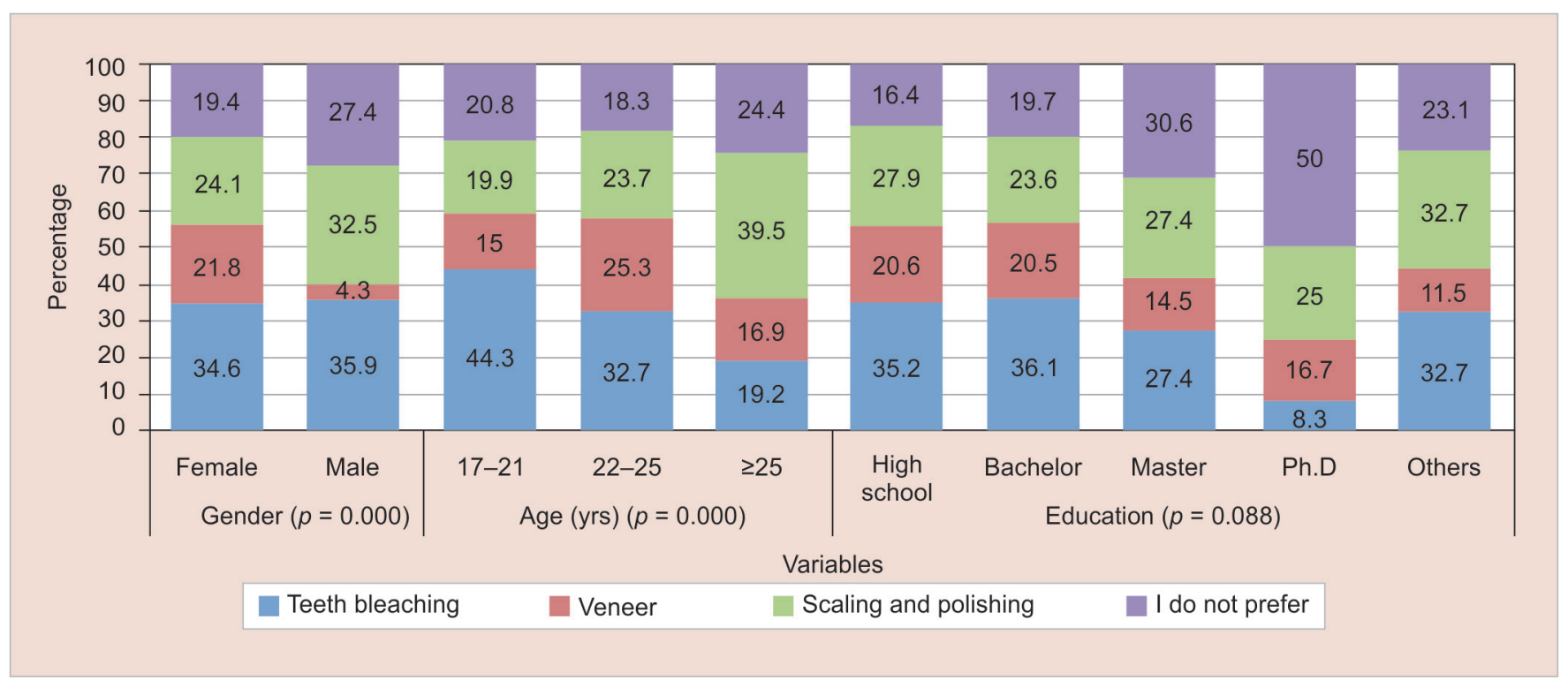

Fig. 3: Esthetic treatment preferences among study subject

Differences in these reported findings suggest that shade and color of the teeth are based on the self-perception and are subjective in nature.

It is normally considered that females are more particular in their appearance than male. Hence, it can be speculated that any physical disturbance affects female's self-esteem more than male's. This study did not show any significant difference with regard to the satisfaction of tooth color between genders. However, females were more dissatisfied with color shade compared to the males. 
This agrees well with the idea that physical injury affects women's self-esteem more than men's. The conducted study did not reveal statistical significance with respect to gender in any of the examined parameters but female participants were more dissatisfied with their dental appearance and esthetics $(53.2 \%)$ as compared with male ones (46.8\%). The desire for teeth alignment is higher among women, being $57.3 \%$, compared to $42.7 \%$ in men. Desire for esthetic dental treatment is also higher in women with $54.8 \%$ compared to $45.2 \%$ in men.

This study demonstrated that high percentage of females compared to the males was not satisfied with the appearance of their teeth without any significant difference between male and female. Participants with bachelor degree of education showed significantly higher percentage of satisfaction when compared to other educational levels. This finding is similar to the Serbian study. ${ }^{14}$

Whenever dental esthetic was discussed, the color of the teeth was considered as a major factor. Participants in previous studies have shown their interest toward improving their appearance by teeth whitening. ${ }^{18}$ In our study, more females compared to the males were dissatisfied with the shade of the teeth. This finding is in line with the Turkish and Serbian studies in which females demonstrated higher dissatisfaction compared with males with no significant differences. ${ }^{14,15}$ However, Malaysian study showed significantly higher dissatisfaction of teeth color among females compared to the males with significant differences between them. ${ }^{19}$ In our study, home bleaching and crest whitening strips were significantly used by the females as a method for tooth whitening.

Younger subjects are significantly more concerned with the white color of the teeth and teeth whitening procedure compared to the older age groups. The individual perception of white teeth are beautiful is reduced with increasing age. ${ }^{20}$ Therefore, older people are more satisfied with their existing dental appearance and not preferring tooth whitening treatment. ${ }^{21}$ Satisfaction with dental appearance and color of teeth was reported in older Croatian and United Kingdom populations. ${ }^{22,23}$ The tooth color changes are more obvious with increasing age, and the level of acceptance to this is common among elderly participants compared to the younger age groups. It can be argued that advanced cognition may dominate effects of cultural or behavioral factors that have effect on selfperception of appearance. ${ }^{14}$

In this study, high percentage of participants with bachelor's level of education was significantly more satisfied with their dental appearance during smiling compared to the other educational categories, while tooth color did not show to vary between different educational levels. On the contrary, previous reports have suggested that respondents with high education levels were more satisfied with the color of their teeth and had no desire for whiter teeth than those with lower levels of education. ${ }^{15,16}$ This finding suggests higher self-satisfaction with the appearance of teeth seen in respondents with bachelor's degree reflecting higher self-esteem. In this study, most of the study participants had bachelor's degree qualification with self-satisfaction with the color of teeth. On the contrary previous study pointed out no relationship between satisfaction with dental esthetic and educational level of the respondents. ${ }^{19}$ Gummy smile showed significant difference between genders while pointed canines and wide smile were found to be significantly different across different age groups. Additionally, gender and age categories showed significant differences in esthetic treatment preferences of the study participants. These findings are suggestive of self-perception of the smile among the study participants.

\section{Conclusion}

The findings of this study revealed that females are more concerned with the color of their teeth and teeth whitening procedures. Younger age groups tend to be more dissatisfied with the color the teeth and are more likely to seek tooth whitening procedures. Respondents with bachelor degree were more satisfied with their dental appearance and esthetics than those with other levels of education. Dentist should have prior knowledge of patient's perception of teeth color and dental appearance. Hence, understanding the layperson's opinion about the color of the teeth and appearance is important parameter while planning esthetically pleasing smile to the patients. However, further larger studies are needed to augment the findings of our study.

\section{References}

1. Muhammad S, Shahid R, Siddiqui MS. Tooth morphology and esthetics while smiling in accordance to golden proportion. Pak J Med Health Sci 2016;10(1):281-284.

2. Rifkin R. Facial analysis: a comprehensive approach to treatment planning in esthetic dentistry. Pract Periodontics Aesthet Dent 2000;12(9):865-871.

3. Reddy TVK, Dhanasekaran S. The golden proportion. J Oper Dent Endod 2017;2(3):79-83.

4. Saha MK, Khatri M, Saha SG, et al. Perception of acceptable range of smiles by specialists, general dentists and lay persons and evaluation of different esthetic paradigms. J Clin Diagn Res 2017;11(2): ZC25-ZC28. DOI: 10.7860/JCDR/2017/23359.9274.

5. AlJehani YA, Baskaradoss JK, Geevarghese A, et al. Current trends in esthetic dentistry. Health 2014;6(15):1941. DOI: 10.4236/ health.2014.615227.

6. Lawson J, Warren JJ, Levy SM, et al. Relative esthetic importance of orthodontic and color abnormalities. Angle Orthod 2008;78(5): 889-894. DOI: 10.2319/080207-361.1.

7. Labban N, Al-Otaibi $\mathrm{H}$, Alayed A, et al. Assessment of the influence of gender and skin color on the preference of tooth shade in Saudi population. Saudi Dent J 2017;29(3):102-110. DOI: 10.1016/ j.sdentj.2017.05.001.

8. Ghani B, Jouhar R, Ahmed N. Relationship of facial skin complexion with gingiva and tooth shade on smile attractiveness. J Interdiscipl Med Dent Sci 2016;4(205):2.

9. Rekow ED. High-technology innovations-and limitations-for restorative dentistry. Dent Clin North Am 1993;37(3):513-524.

10. Bichacho N. Porcelain laminates: integrated concepts in treating diverse esthetic defects. Pract Periodontics Aesthetic Dent 1995;7(3):13-23.

11. Hornbrook DS, Hastings JH. Use of bondable reinforcement fiber for post and core build-up in an endodontically treated tooth: maximizing strength and esthetics. Pract Periodontics Aesthetic Dent 1995;7(5):33-42.

12. Derbabian K, Marzola R, Donovan TE, et al. The science of communicating the art of esthetic dentistry. Part II: diagnostic provisional restorations. J Esthet Dent 2000;12(5):238-247. DOI: 10.1111/j.1708-8240.2000.tb00230.x.

13. Maghaireh GA, Alzraikat H, Taha NA. Satisfaction with dental appearance and attitude toward improving dental esthetics among patients attending a dental teaching center. J Contemp Dent Pract 2016;17(1):16-21. DOI: 10.5005/jp-journals-10024-1796.

14. Strajnić $L$, Bulatović $D$, Stančić l, et al. Self-perception and satisfaction with dental appearance and esthetics with respect to patients' age, gender, and level of education. Srp Arh Celok Lek 2016;144(11-12): 580-589. DOI: 10.2298/SARH1612580S.

15. Akarslan ZZ, Sadik B, Erten H, et al. Dental esthetic satisfaction, received and desired dental treatments for improvement of esthetics. Indian J Dent Res 2009;20(2):195-200. DOI: 10.4103/0970-9290. 52902. 
16. Xiao J, Zhou XD, Zhu WC, et al. The prevalence of tooth discoloration and the self-satisfaction with tooth color in a Chinese urban population. J Oral Rehabil 2007;34(5):351-360. DOI: 10.1111/j.13652842.2007.01729.x.

17. Odioso LL, Gibb RD, Gerlach RW. Impact of demographic, behavioral, and dental care utilization parameters on tooth color and personal satisfaction. Compend Contin Educ Dent Suppl 2000(29):S35-S41; quiz S43.

18. Samorodnitzky-Naveh GR, Geiger SB, Levin L. Patients' satisfaction with dental esthetics. J Am Dent Assoc 2007;138(6):805-808. DOI: 10.14219/jada.archive.2007.0269.

19. Tin-Oo MM, Saddki N, Hassan N. Factors influencing patient satisfaction with dental appearance and treatments they desire to improve esthetics. BMC Oral Health 2011;11:6. DOI: 10.1186/1472-6831-11-6.
20. Vallittu PK, Vallittu AS, Lassila VP. Dental esthetics-a survey of attitudes in different groups of patients. J Dent 1996;24(5):335-338. DOI: 10.1016/0300-5712(95)00079-8.

21. Meng X, Gilbert GH, Litaker MS. Dynamics of satisfaction with dental appearance among dentate adults: 24 -month incidence. Community Dent Oral Epidemiol 2008;36(4):370-381. DOI: 10.1111/j.16000528.2007.00409.x.

22. Alkhatib MN, Holt R, Bedi R. Prevalence of self-assessed tooth discoloration in the United Kingdom. J Dent 2004;32(7):561-566. DOI: 10.1016/j.jdent.2004.06.002.

23. Lajnert $\mathrm{V}$, Pavičić $\mathrm{DK}$, Gržić $\mathrm{R}$, et al. Influences of age and maxillary anterior teeth status on patient's satisfaction with dental appearance and tooth color. Gerodontology 2012;29(2):e674-e679. DOI: 10.1111/j.1741-2358.2011.00543.x. 


\section{Questionnaire}

1. Gender

- Male

- Female

2. Age

- 17-21 years

- 22-25 years

- 25 years and above

- Other

3. Are you satisfied with the color shade of your teeth?

- Yes

- No

- Yes, but I wish they were whiter

4. How would you rate your knowledge about teeth whitening procedures?

- None

- I know some

- Good

5. Have you ever tried a whitening procedure on your teeth before?

- Yes

- No

6. If yes, which method have you used?
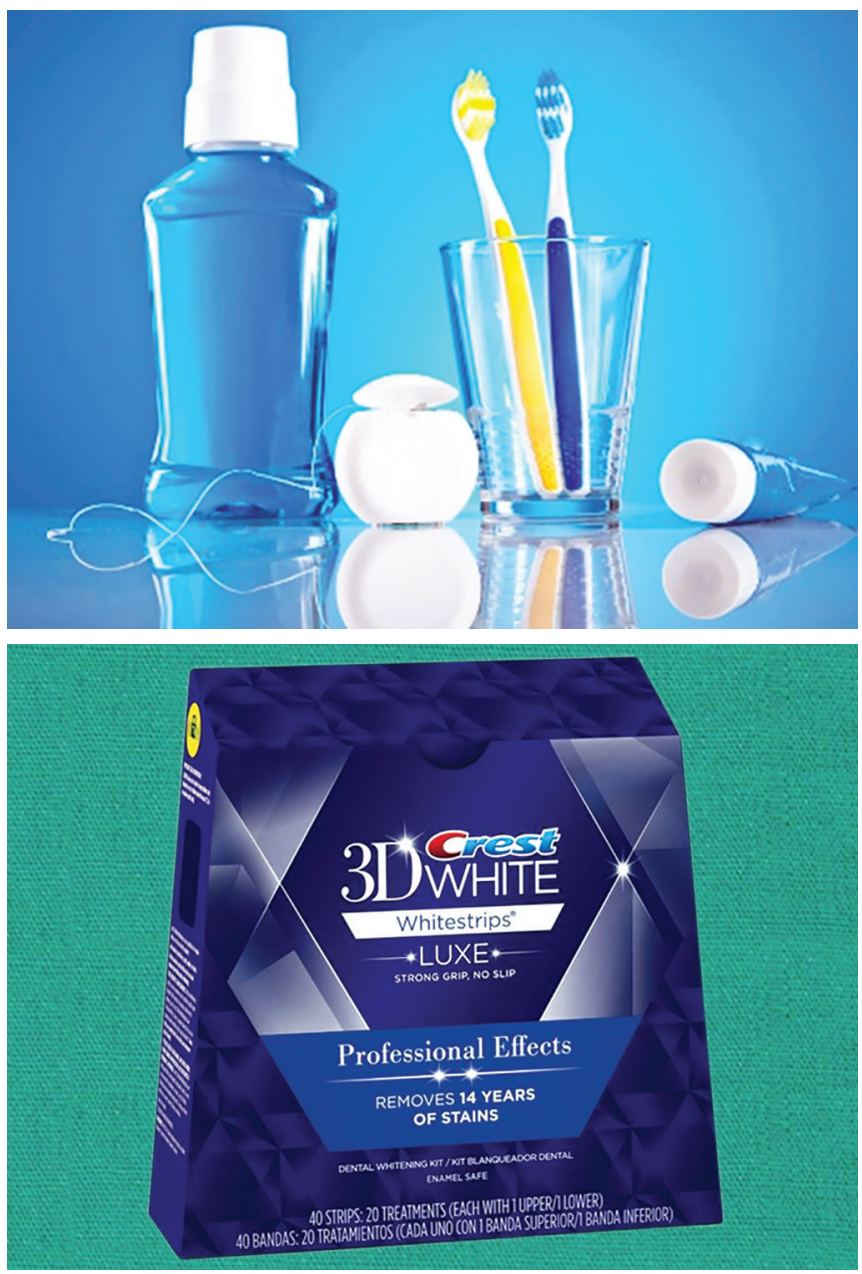
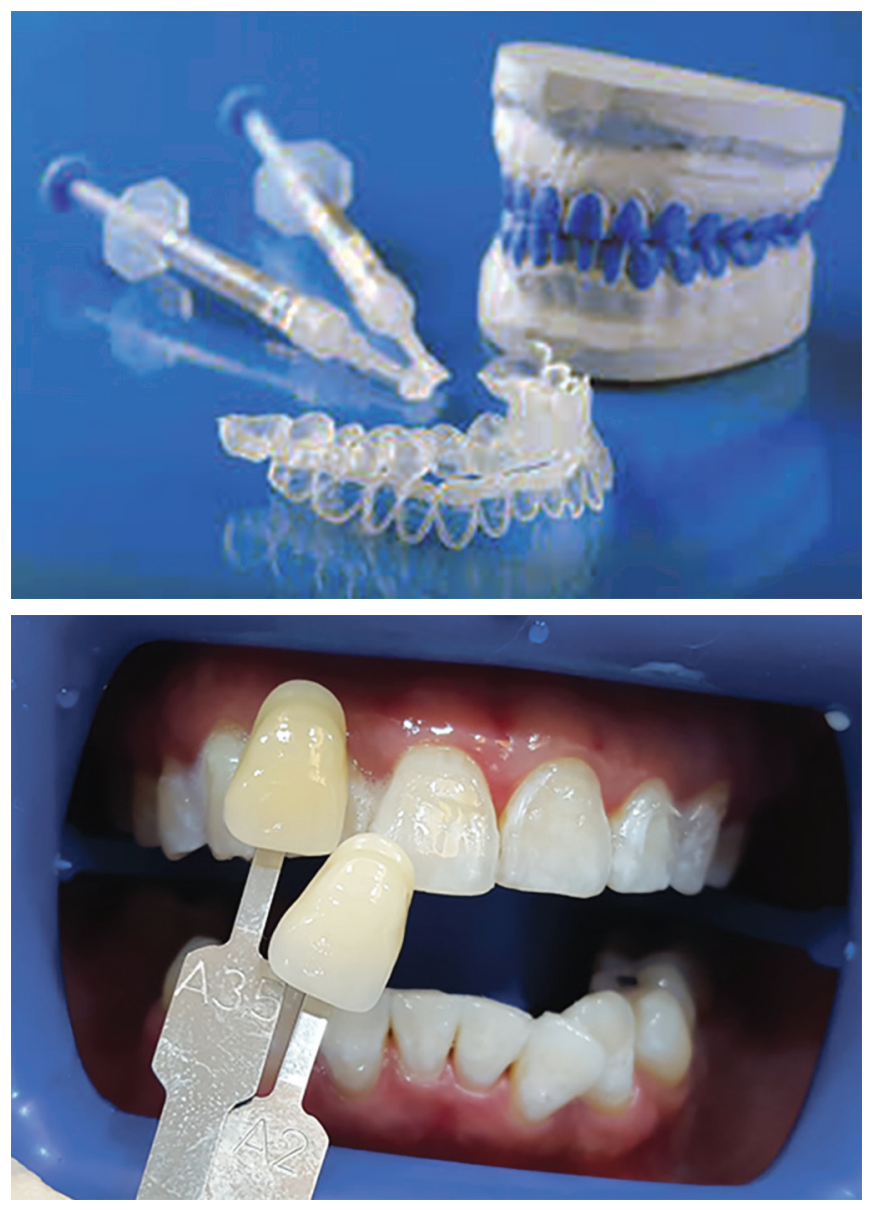

7. Do you consider Porcelain Veneers as whitening procedure method?

- Yes

- No

- Probably

- I do not know

8. Are you satisfied of how your teeth appear while smiling?

- Yes

- No

- Yes, but it needs some little improvements

9. Is there any part of your smile you would like to change?

- Yes

- No 
10. Following are some pictures of different smile, rate on a scale from 0 to 5 (0: least attractive, 5 most attractive)

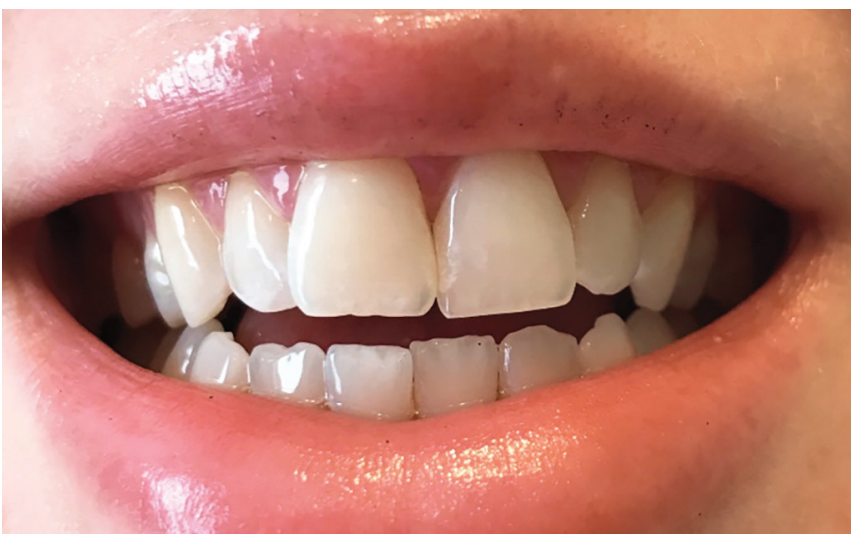

- 0 (least attractive)

- 1-2 (not very attractive)

- 2-3 (slightly attractive)

- 4-5 (very attractive)

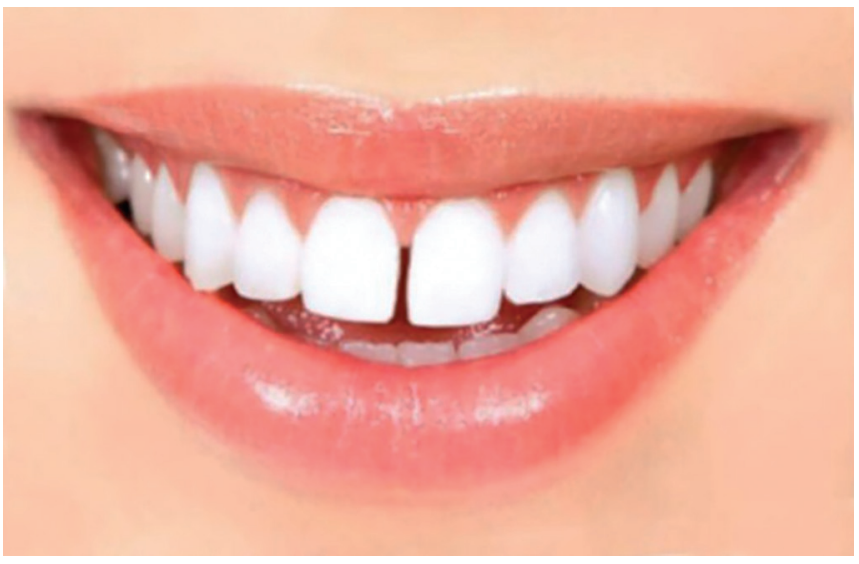

- 0 (least attractive)

- 1-2 (not very attractive)

- 2-3 (slightly attractive)

- 4-5 (very attractive)

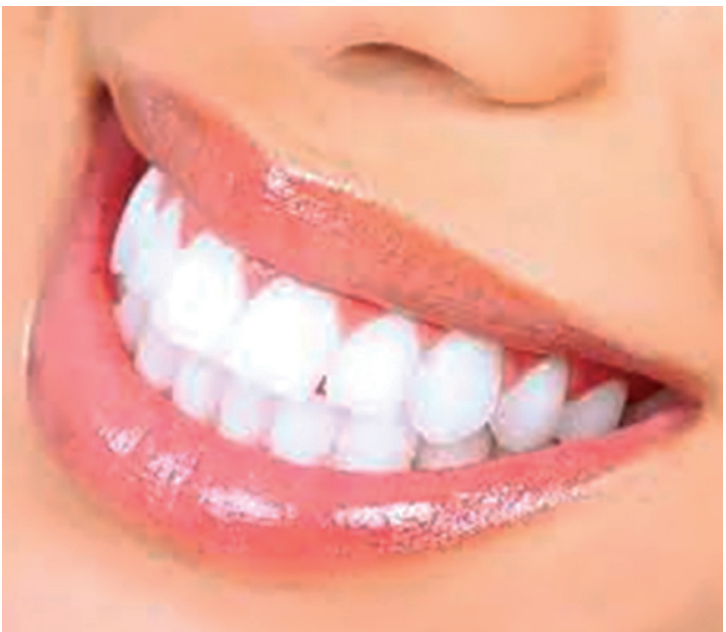

- 0 (least attractive)

- 1-2 (not very attractive)

- 2-3 (slightly attractive)

- 4-5 (very attractive)

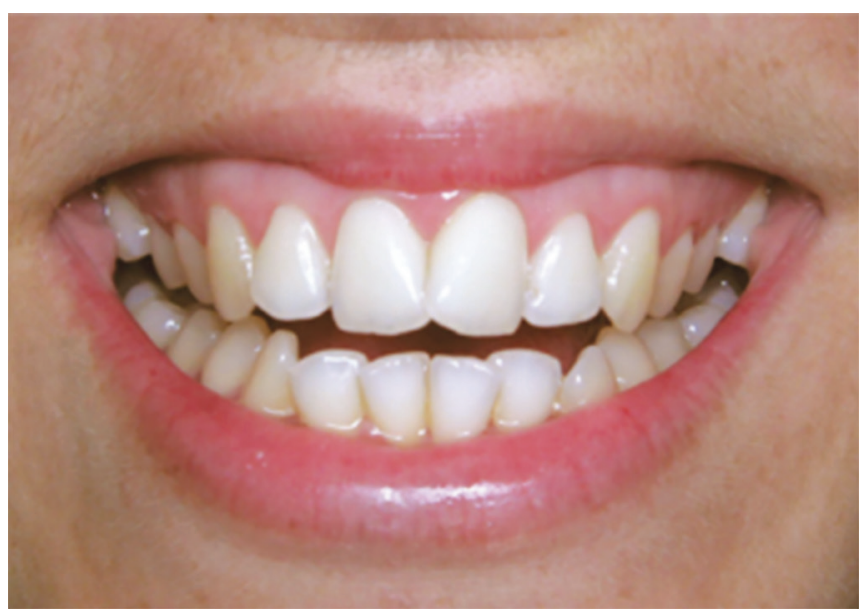

- 0 (least attractive)

- 1-2 (not very attractive)

- 2-3 (slightly attractive)

- 4-5 (very attractive)

11. In your personal opinion, do you consider pointed canines as a feature of attractiveness?

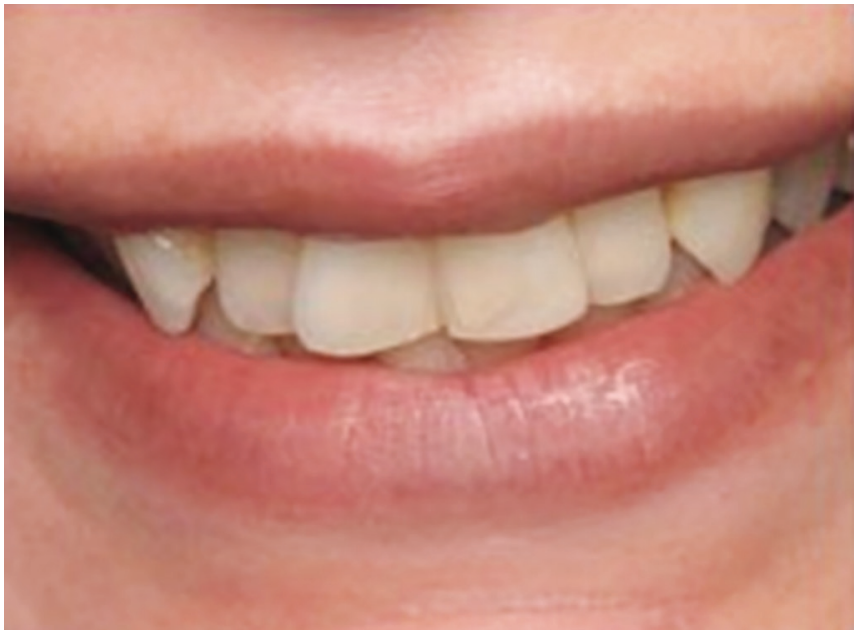

- Yes, very

- Not very

- Ido not prefer

- It is not attractive 
12. In your personal opinion, do you consider gummy smiles as a feature of attractiveness?

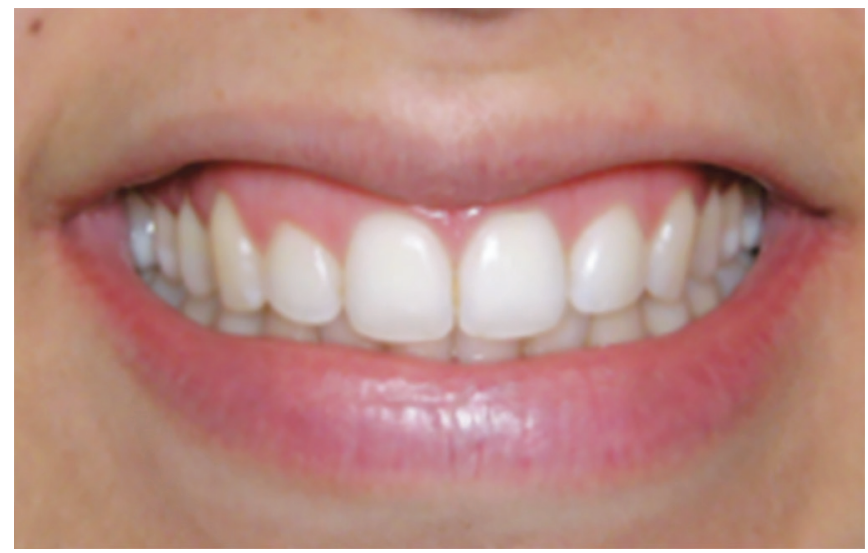

- Yes, very

- Not very

- I do not prefer

- It is not attractive

13. In your personal opinion, do you consider overly white teeth as a feature of attractiveness?

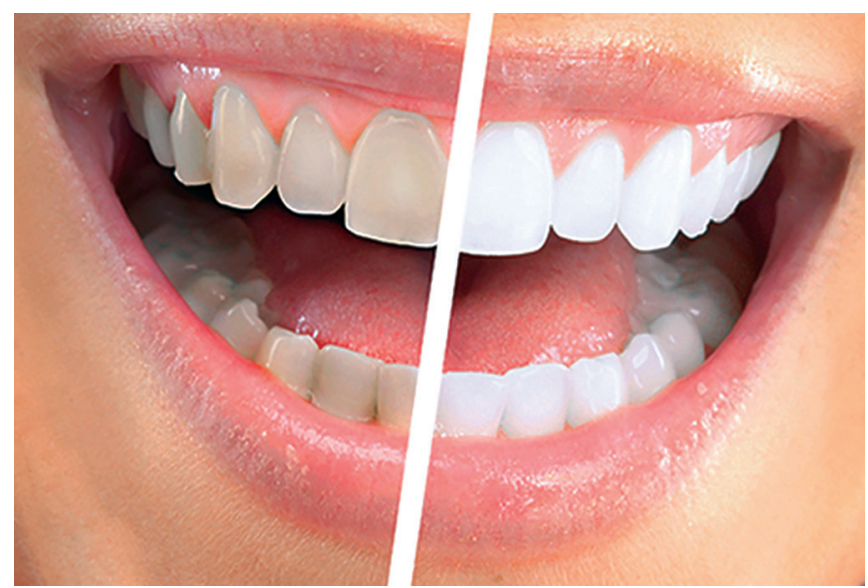

- Yes, very

- Not very

- I prefer natural white

- It is not attractive
14. In your personal opinion, select the color of teeth that you find most attractive
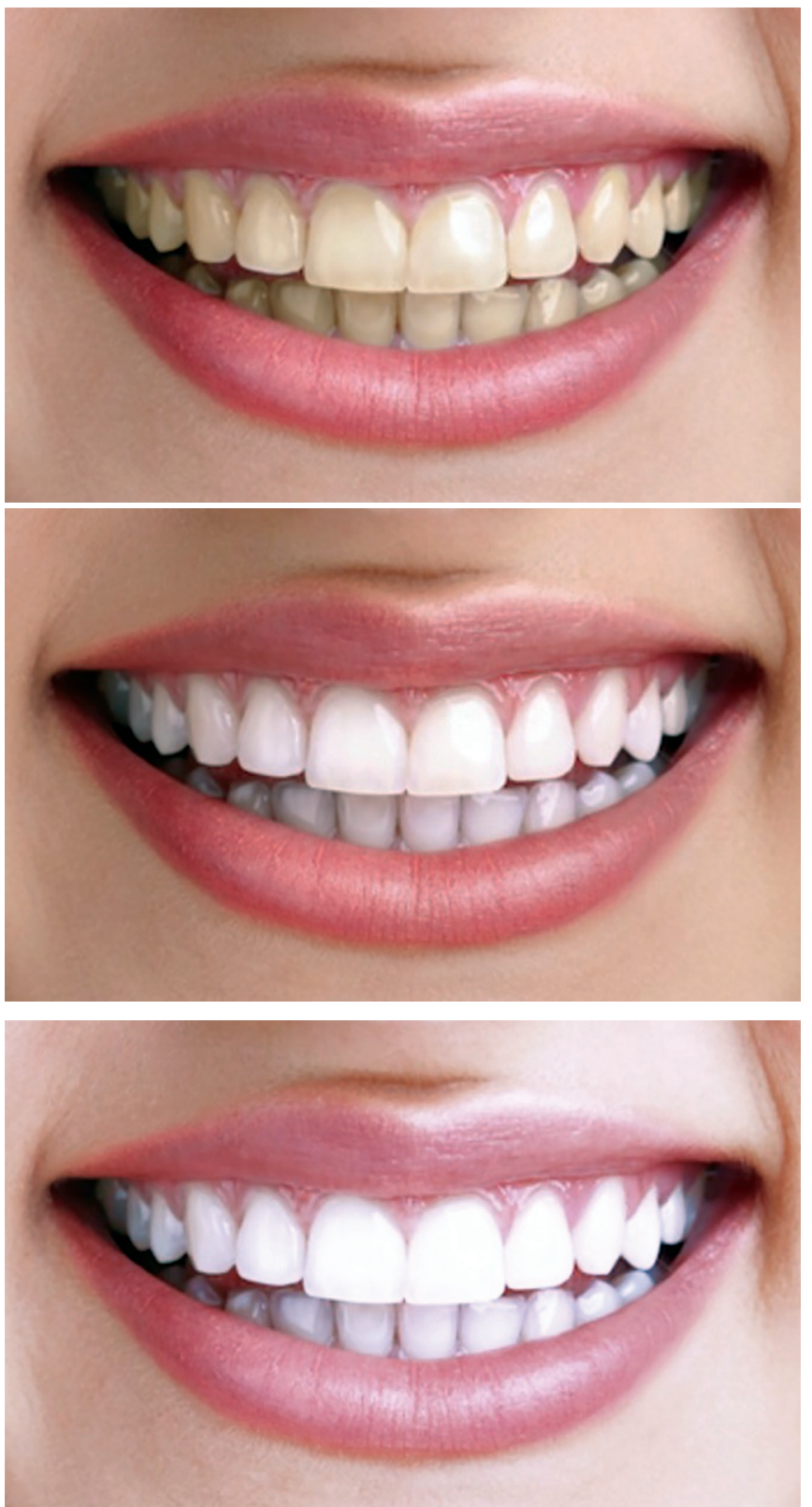